\title{
Refractive Errors Progression in Brazilian Low-Income School Children
}

Research Article

Célia R. Nakanami ${ }^{1 *}$, Adriana Berezovsky ${ }^{1}$, Nivea N. Cavascan ${ }^{1}$, Márcia R. Mitsuhiro ${ }^{1}$, Sung E. Watanabe ${ }^{1}$, Paula Y. Sacai ${ }^{1}$, Josenilson M. Pereira ${ }^{1}$, Sergio Muñoz ${ }^{2}$, Rubens Belfort $\mathrm{Jr}^{2}$, Solange R. Salomão

${ }^{1}$ Departamento de Oftalmologia e Ciências Visuais, Escola Paulista de Medicina, Universidade Federal de São Paulo, São Paulo, SP, Brazil.

${ }^{2}$ Departamento de Salud Publica, Universidad de La Frontera, Temuco, Chile.

\section{Abstract}

Purpose: To assess the progression of refractive error (RE) in low-income school children in Sao Paulo, Brazil.

Methods: The study population consisted of a cohort of children (11-14 years of age) from 9 randomly chosen public schools from a study performed in 2004-2005, with refraction in those with visual impairment (uncorrected distance visual acuity $\leq 20 / 40$ in either eye). Eligible participants were those identified in the baseline study as visually impaired. Three years later, follow-up recruitment consisted of invitation for a free ophthalmic exam in the school facilities. Cycloplegic auto-refraction, cycloplegic subjective refraction and fundus examination were performed in those refracted at baseline and follow-up. Risk factors for refractive errors were investigated by administering questionnaires on family demographics, parental glasses usage and near work/outdoor activities.

Results: A cohort of 218 children was eligible for a 3-year follow-up, with 136 examined. Myopic progression of -0.50 to -1.49 spherical equivalent (SE) was found in both eyes of $64(47.1 \%)$ children, in $22(16.2 \%)$ firstly right eyes tested only and in $15(11.0 \%)$ second eyes tested only. Both eyes of $14(10.3 \%)$ children had progressed

$<-1.50 \mathrm{SE}$, with $11(8.1 \%)$ progressing only in their second eyes tested and $6(4.4 \%)$ in their first eye tested. In multiple regression analysis myopic progression was associated with both parents wearing glasses $(\mathrm{p}<0.05)$.

Conclusions: Very mild refractive error progression was detected in a low-income urban Brazilian school children population, confirming the previous finding of low prevalence of refractive errors leading to visual impairment in this population.

Keywords: Refractive Errors; School Children; Myopia; Progression; Risk Factors; Low income Population.

\section{Introduction}

Uncorrected refractive errors (RE) are one of the major causes of avoidable visual impairment and blindness worldwide [1]. Schoolage children constitute a particularly vulnerable group, where uncorrected RE may have a dramatic impact on learning capability and educational potential. Previous population-based Refractive Error Study in Children (RESC) surveys have conclusively shown that refractive error (myopia) is mainly a problem among children attending schools [2-9]. On the basis of these findings, three subsequent RESC surveys, one in rural Yangxi, China [10], one in Kathmandu, Nepal [11] and one in Sao Paulo, Brazil [12] were designed with logistically less cumbersome, school-based sampling. Further, because of resistance among parents in providing consent for cycloplegia, in these surveys only children with visual impairment were evaluated with cycloplegic refraction [10-12].

It has also been shown that there are risk factors for myopia progression. Among them are the amount of outdoor activity, near work and educational/socio economic status of the family, probably related to the emphasis on reading and other near vision tasks associated with school performance [13]. It has been consistently shown that myopia prevalence is higher among those with myopic parents compared to those without any parental/sibling history of myopia [14].

The purpose of this follow-up study of the RESC Brazil survey was to assess the progression of refractive error in a sample of low-income school children with vision impairment (VI) in the city of Sao Paulo along with possible associated factors as near work and parents' characteristics.

*Corresponding Author:

Dr. Celia R. Nakanami,

Departamento de Oftalmologia e Ciências Visuais, Escola Paulista de Medicina, Universidade Federal de São Paulo, São Paulo, SP, Brasil.

Tel: +55-11-55764848; ext. 2280

E-mail: ssalomao@unifesp.br

Received: March 31, 2016

Accepted: May 18, 2016

Published: May 20, 2016

Citation: Célia R. Nakanami, et al., (2016) Refractive Errors Progression in Brazilian Low-income School Children. Int J Opthalmol Eye Res, S6:002, 4-10. doi: http://dx.doi.org/10.19070/2332-290X-SI06002

Copyright: Célia R. Nakanami ${ }^{\circ}$ 2016. This is an open-access article distributed under the terms of the Creative Commons Attribution License, which permits unrestricted use, distribution and reproduction in any medium, provided the original author and source are credited. 


\section{Methods}

\section{Study design}

In this longitudinal cohort study, children enrolled in the RESC Brazil study [12] in 2004-2005 were re-contacted 3 years later for reexamination, between September 2008 and December 2009. The baseline study sample of school children 11 to 14 of age was selected randomly using school-based cluster sampling [12].

\section{Recruitment}

School authorities from the 9 schools participants in the baseline study were contacted and informed about the follow-up study. Through an online registration system the school heads had access to information of the students registered in the public school system in the area. After tracking the school children enrolled in the baseline study, a list of those still registered in the system was provided. These students were contacted in their current school for the invitation to participate in the follow-up study. Those who were not listed were tracked by household interview using the address provided in the baseline study.

All components of the follow-up examination were carried out at the child's school, as in the baseline survey. The tenets of the Declaration of Helsinki were observed and approval was granted by the Committee on Ethics in Research of UNIFESP and also from the WHO Secretariat Committee on Research Involving Human Subjects. Informed consent for the follow-up examination was obtained from the child's parent through a written form sent to each home in advance by the school head. Those subjects aged 18 years and older provided their own informed consent.

\section{Clinical Eye Exam}

A full description of the clinical eye examination can be found elsewhere [12]. Briefly presenting visual acuity (PVA) and for those wearing glasses uncorrected visual acuity (UVA) were measured in each eye, firstly the right eye, by ophthalmic technologists using a retro-illuminated logMAR tumbling-E chart for $4 \mathrm{~m}$. Cycloplegia was induced with 2 drops of $1 \%$ cyclopentolate, administered 5 minutes apart, with a third drop administered after 15 minutes. Cycloplegia and pupil dilation were evaluated after an additional 20 minutes. Pupillary dilation of $6 \mathrm{~mm}$ or more with absence of light reflex was considered complete cycloplegia. Autorefraction was performed with a handheld refractor (Retinomax Plus; Nikon, Tokyo, Japan) by an ophthalmic technologist. Subjective cycloplegic refraction and indirect ophthalmoscopic examination of the media and fundus were performed by an ophthalmologist.

\section{Risk Factors Questionnaire}

A detailed questionnaire was administered to each participant through an individual interview to obtain information on family demographics, parental glasses usage for distance and near and participant's near work/outdoor activities. For the latter an adapted version of a previous questionnaire used in studies in Australia and Singapore $[15,16]$. The questionnaire was translated to the Portuguese language and then re-translated to the English language by one of the authors who is an official translator (SRS).
Participant's activities included hours spent indoors and outdoors both in a typical school day and in a typical weekend day. Activities included reading for pleasure, reading for study/work, computers for study/work/pleasure, television viewing/movies and sports.

\section{Data Management and Analysis}

Data forms were reviewed for accuracy and completeness in the field before computer data entry at UNIFESP. Data ranges, frequency distributions, and consistency among related measurements were checked with computerized data-cleaning programs. Statistical analyses were performed with commercial software STATA 12.0 [17]. Estimates of refractive error were based on measurement with cycloplegic autorefraction. Myopia was defined as spherical equivalent (SE) refractive error of at least -0.50 $\mathrm{D}$ and hyperopia as $+2.00 \mathrm{D}$ or more. Children were considered myopic if one or both eyes were myopic and hyperopic if one or both eyes were hyperopic, so long as neither eye was myopic. Astigmatism was investigated at cylinder values of $-0.75,-0.75$ to $-1.50,-1.50$ to -2.00 , and -2.00 D. Changes in refractive error were analyzed with respect to gender, age and the amount of refractive error at baseline. Multiple logistic regression was used to investigate the association of these covariates with myopic progression, using progression thresholds of $-0.50 \mathrm{D}$ and $-1.50 \mathrm{D}$. Changes in astigmatism were similarly investigated.

\section{Results}

In the original RESC survey in 2004-2005, 2825 children between 11 and 14 years were enumerated and 2441 were examined [12]. Out of these, only 218 had cycloplegic refraction due to uncorrected visual acuity of 20/40 or worse in at least in one eye. So, our baseline sample is composed of these 218 children. At the follow-up study some of those 218 originally examined were no longer attending the same school or had left area. Data showing the distribution according to age and gender from baseline and follow-up groups can be found in Table 1.

In order to investigate the representativeness of those examined, an analysis including baseline data from 138 attending the followup examination comparing with 80 who have not attended was performed. There were no statistical differences in baseline data regarding cluster, age, gender, refractive status (myopia, emmetropia and hyperopia), mean refractive error (spherical equivalent) of those who remained in the study and those who were lost to follow-up. Since respondents and non-respondents to follow-up exam had comparable data, it was inferred that the follow-up sample was representative of the baseline sample for refractive error progression analysis. A summary of these comparisons is shown in Table 2.

\section{Progression of Refractive Errors}

Follow-up examinations took place an average of 40.9 months (standard deviation ([SD] $=6.0$ months) after the initial examination at baseline. Of those with follow-up examinations $58.7 \%$ were females. Two of the 138 participants with follow-up examinations were excluded. Both were 11-year-old females in the baseline: one refused cycloplegia in the follow-up and the other provided unreliable visual acuity data in the baseline. The latter presented with $20 / 20$ uncorrected visual acuity in both eyes in 
Table 1. Distribution of participants examined in baseline and follow-up according to gender and age.

\begin{tabular}{|c|c|c|c|}
\hline & $\begin{array}{c}\text { Examined at } \\
\text { Baseline N (\%) }\end{array}$ & Percent Examined & $\begin{array}{c}\text { Examined at } \\
\text { Follow-up N (\%) }\end{array}$ \\
\hline Gender & \multicolumn{3}{|l}{} \\
\hline Male & $91(41.7)$ & 62.6 & $57(41.3)$ \\
\hline Female & $127(58.3)$ & 63.8 & $81(58.7)$ \\
\hline Age & \multicolumn{3}{|l}{} \\
\hline 11 & $49(22.5)$ & 69.4 & $34(24.6)$ \\
\hline 12 & $58(26.6)$ & 72.4 & $42(30.4)$ \\
\hline 13 & $53(24.3)$ & 50.9 & $27(19.6)$ \\
\hline 14 & $58(26.6)$ & 60.3 & $35(25.4)$ \\
\hline All & $218(100.0)$ & 63.3 & $138(100.0)$ \\
\hline
\end{tabular}

Table 2. Comparison of respondents and non-respondents for the follow-up exam according to gender, age and type of ametropia from the baseline study.

\begin{tabular}{|c|c|c|c|}
\hline & $\begin{array}{c}\text { Respondents } \\
\text { N (\%) }\end{array}$ & $\begin{array}{c}\text { Non-Respondents } \\
\text { N (\%) }\end{array}$ & P value \\
\hline Gender & \multicolumn{3}{|l|}{} \\
\hline Male & $57(41.3)$ & $34(42.5)$ & $\mathrm{P}=0.86$ \\
\hline Female & $81(58.7)$ & $46(57.5)$ & \\
\hline Age & \multicolumn{3}{|l|}{} \\
\hline 11 & $34(24.6)$ & $15(18.8)$ & $\mathrm{P}=0.09$ \\
\hline 12 & $42(30.4)$ & $16(20.0)$ & \\
\hline 13 & $27(19.6)$ & $26(32.5)$ & \\
\hline 14 & $35(25.4)$ & $23(28.8)$ & \\
\hline Ametropia & \multicolumn{3}{|l}{} \\
\hline Myopia & $85(61.6)$ & $47(58.8)$ & $\mathrm{P}=0.53$ \\
\hline Emmetropia & $18(13.0)$ & $16(20.0)$ & \\
\hline Hyperopia & $35(25.4)$ & $17(21.2)$ & \\
\hline All & $138(100.0)$ & $80(100.0)$ & \\
\hline
\end{tabular}

the follow-up exam.

Table 3 shows refractive status distribution (myopia, emmetropia or hyperopia) from the 136 participants. Change in spherical equivalent refraction during the follow-up interval ranged from $-4.00 \mathrm{D}$ to $+1.75 \mathrm{D}$, with a mean of $-0.79 \mathrm{D}(\mathrm{SD}, 0.88)$ for both first and second eyes tested. The extremes included, for example, 5 eyes of 4 children with myopic shift of $-3.00 \mathrm{D}$ or less. These eyes were both myopic in one male with myopic anisometropia. He showed up without his glasses in the follow-up exam. A second case of myopic anisometropia showed this substantial progression in the more ametropic eye in a female. A macular elevation most likely due to retinal pigmented epithelium abnormality secondary to uveitis was found in the formerly hyperopic second eye of a female. Among cases with hyperopic shift (those becoming more positive), 1 first eye and 2 second eyes tested had changes of more than $+1.00 \mathrm{D}$ : both eyes of a mildly myopic female who refused to wear glasses in the interval of baseline and follow-up and the second eye tested of a male with myopic anisometropic amblyopia in the baseline.

The distribution of change in refractive error by age at baseline in first and second eyes tested of males and females is shown in Figure 2 with an overall mean change of $-0.74 \mathrm{D}$ (SD, 0.84). The mean change in first eyes tested was -0.73 (SD, 0.81) in males (95\% Confidence Interval [CI], -0.94 -0.51) and $-0.77 \mathrm{D}$ (SD, 0.78) in females $(95 \% \mathrm{CI},-0.95-0.60)$. Second eyes tested were similar.

The magnitude of astigmatic error showed over the 40.9-month period was an estimated mean change of -.165 D (SD, 0.74) in first eyes tested, and an estimated mean change of -.169 D (SD, 0.80) in second eyes tested. Figure 2 shows the change in astigmatic error within each of four categories of astigmatism at baseline. Substantial progression of the astigmatic component was found in the second eye of a high myopic male. This patient was further evaluated with keratometry and his measurements were compatible of keratoconus grade II in both eyes (OD 45.62/49.00; OS $45.00 / 49.62)$, meeting the criteria for clinical classification of keratoconus [18].

Progression of -0.50 to -1.49 SE was found in both eyes of 64 $(47.1 \%)$ children, in $22(16.2 \%)$ first eyes tested only and in 15 $(11.0 \%)$ second eyes tested only. Both eyes of $14(10.3 \%)$ children had progressed $\leq-1.50 \mathrm{SE}$, with $11(8.1 \%)$ progressing only 
Table 3. Number (\%) of children with ametropia at baseline and at follow-up.

\begin{tabular}{|c|c|c|c|c|}
\hline & \multicolumn{4}{|c|}{ Follow-up } \\
\cline { 2 - 5 } & Hyperopes & Emmetropes & Myopes & All \\
\hline Baseline & \multicolumn{4}{|c|}{} \\
\hline Hyperopes & $28(80.0)$ & $7(20.0)$ & $0(0.0)$ & $35(25.7)$ \\
\hline Emmetropes & $2(13.3)$ & $10(66.7)$ & $3(20.0)$ & $15(11.0)$ \\
\hline Myopes & $0(0.0)$ & $0(0.0)$ & $86(100.0)$ & $86(63.3)$ \\
\hline All & $30(22.1)$ & $17(12.5)$ & $89(65.4)$ & $136(100.0)$ \\
\hline
\end{tabular}

Figure 1. Box plot representations of the distribution of change in spherical equivalent refractive error in first and second eyes of male and female subjects as a function of age at baseline.
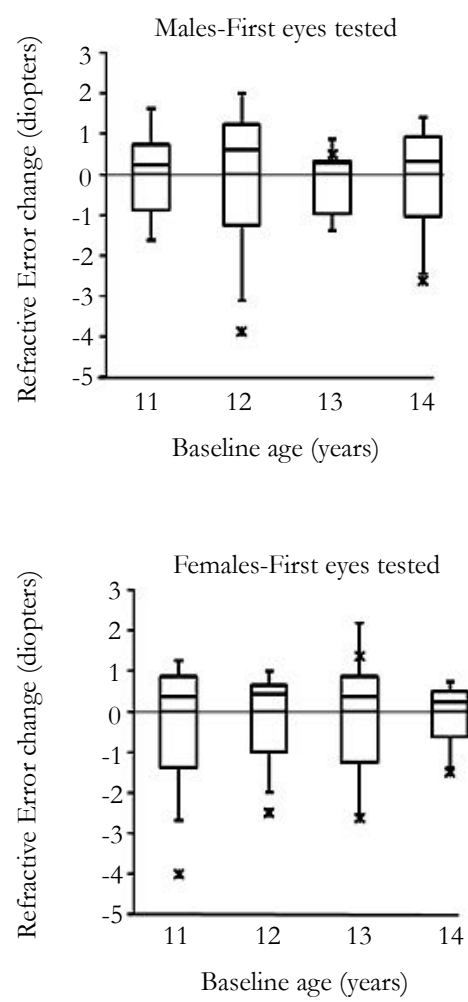

in their second eyes tested and $6(4.4 \%)$ in their first eyes tested.

\section{Risk Factors}

Parental education level was categorized into primary, secondary, high school or better (college, graduate school). Table 4 shows the distribution of parents' educational level and usage of glasses according to the myopia progression cutoff of $-0.50 \mathrm{SE}$ and -1.50 SE in either eye. The association between parents' usage of glasses with both myopia progression cutoffs was investigated using logistic regression model adjusting for parent's education, age and gender. Both parents wearing glasses was significantly associated $(p<0.05)$ with higher probability of progression to $\leq-1.50 \mathrm{SE}$ in the first eyes tested (Odds ratio $=4.19 ; 95 \%$ CI: $1.01-17.45$ ). This analysis was not statistically significant in second eyes tested even though the estimate Odds ratio was $2.40(\mathrm{p}=0.16)$.

Table 5 shows the frequency of near work activities as well as outdoor activities compared to myopia progression cutoff in either eye. Near vision activities (reading for pleasure, reading for study/ work, computer usage) were not associated with -0.50 to $-1.49 \mathrm{SE}$ progression for first and second eyes tested in a multiple logis-
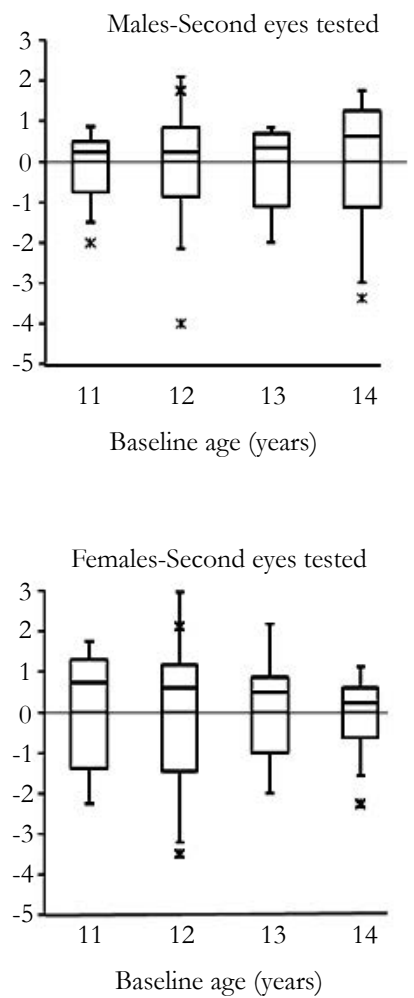

tic regression analysis adjusted for age and gender. The same results were found for progression of -1.50 SE. No association was found between outdoor activities and progression (-0.50 to -1.49 and $-1.50 \mathrm{SE}$ ) by multiple logistic regression analysis adjusted for age and gender for either first or second eyes tested.

\section{Discussion}

This study has provided the first longitudinal population-based study in low income school-age-children, focusing the progression and potential risk factors of refractive error progression in a representative urban area of Brazil. Data from this study showed negative progression (myopic) of refractive errors after a threeyear interval, with around two-thirds of school children $(60.7 \%)$ progressing $-0.50 \mathrm{D}$, and, a smaller percentage $(16.5 \%)$ of those examined progressing $-1.50 \mathrm{D}$.

The current results show that myopia progression was substantially lower in this cohort of low-middle income school children from an urban area of Brazil when compared to school children from other parts of the world, especially those from Asian coun- 
Figure 2. Box plot representations of the distribution of change in astigmatism in first and second eyes of male and female subjects as a function of baseline astigmatism categories. The positive portion of the ordinate indicates increasing astigmatism and the negative portion decreasing astigmatism.
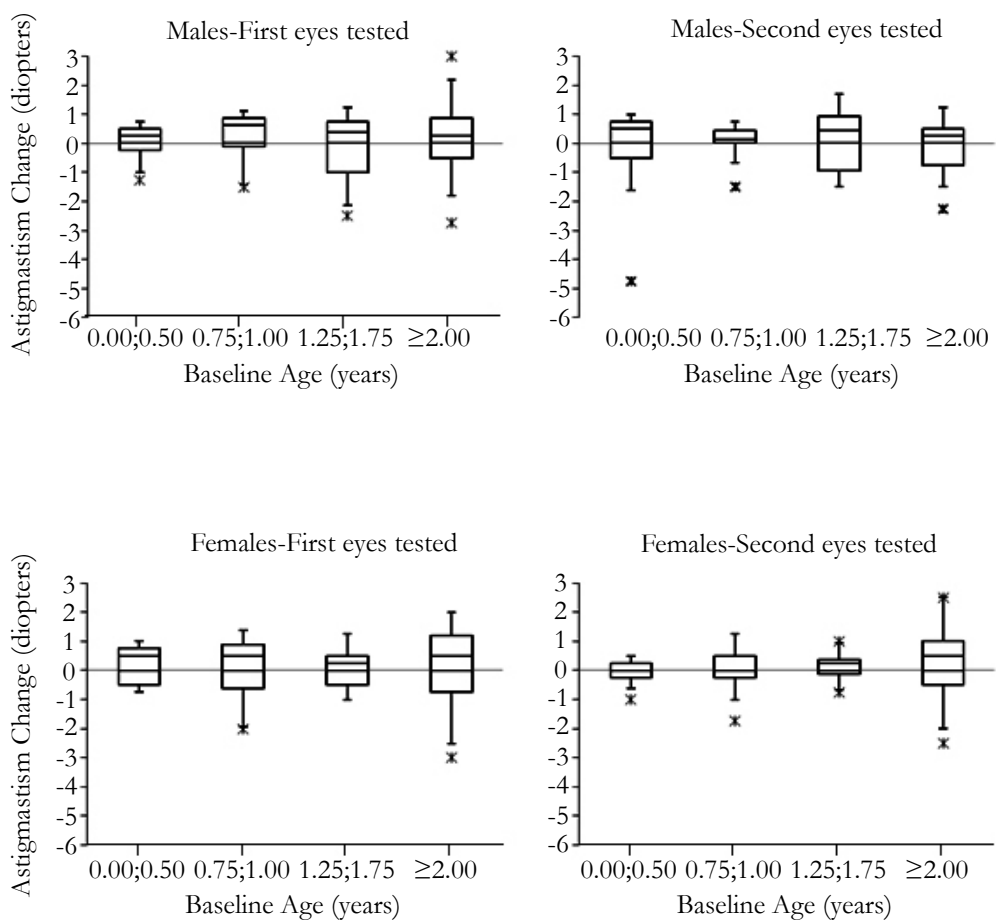

Table 4. Parents' schooling and use of glasses according to myopia progression cutoffs of -0.50 and $-1.50 \mathrm{SE}$ in either eye.

\begin{tabular}{|c|c|c|c|c|c|}
\hline & \multicolumn{2}{|c|}{-0.50 Progression } & \multicolumn{2}{|c|}{-1.50 Progression } & \multirow{2}{*}{$\begin{array}{l}\text { Total } \\
\mathrm{N}(\%)\end{array}$} \\
\hline & $\begin{array}{c}\text { Yes } \\
\text { N (\%) }\end{array}$ & $\begin{array}{c}\text { No } \\
\text { N }(\%)\end{array}$ & $\begin{array}{c}\text { Yes } \\
\text { N }(\%)\end{array}$ & $\begin{array}{c}\text { No } \\
\text { N }(\%)\end{array}$ & \\
\hline \multicolumn{6}{|l|}{ Parents Schooling } \\
\hline Primary & $25(24.8)$ & $8(22.9)$ & $9(29.0)$ & $24(22.9)$ & $33(24.3)$ \\
\hline Secondary & $35(34.6)$ & $9(25.7)$ & $11(35.5)$ & $33(31.4)$ & $44(32.4)$ \\
\hline$\geq$ High School & $28(27.7)$ & $13(37.1)$ & $8(25.8)$ & $33(31.4)$ & $41(30.1)$ \\
\hline Not Informed & $13(12.9)$ & $5(14.3)$ & $3(9.7)$ & $15(14.3)$ & $18(13.2)$ \\
\hline \multicolumn{6}{|c|}{ Parents Wearing Glasses } \\
\hline None & $31(30.7)$ & $12(34.3)$ & $6(19.4)$ & $37(35.2)$ & $43(31.7)$ \\
\hline One & $28(27.7)$ & $13(37.1)$ & $11(35.5)$ & $30(28.6)$ & $41(30.1)$ \\
\hline Both & $38(37.6)$ & $7(20.0)$ & $13(41.9)$ & $32(30.5)$ & $45(33.1)$ \\
\hline Not informed & $4(4.0)$ & $3(8.6)$ & $1(3.2)$ & $6(5.7)$ & $7(5.1)$ \\
\hline Total & $101(100.0)$ & $35(100.0)$ & $31(100.0)$ & $105(100.0)$ & $136(100.0)$ \\
\hline
\end{tabular}

SE - spherical equivalent

tries. To be noted, the studied population was selected from a baseline study in which refraction was performed just in those with some degree of visual acuity impairment [12]. Besides this peculiarity, the difference between the current study and other studies of myopia progression might be related to the higher prevalence of myopia in Southeast Asian achieving more than $70 \%$ in $15-18$ year old school children $[16,18,19]$. In our baseline study, the prevalence of visual impairment attributable to myopia was $5.3 \%[12]$.

Intense schools demands in Asian and high-income countries are also appointed as an environmental factor that contributes sub- stantially to the high prevalence of myopia in these settings [20]. Although evidence that outdoor activities reduce the prevalence of myopia, the progression certainly increases with intense near work activities and lack of outdoor activities in children [15].

However we recognize that the current study has its limitations. A lower response to the clinical exam than expected and the inclusion of only low-middle income participants from public schools should be considered. Despite several attempts to bring the participants of the baseline study to the follow-up eye exam, there was a response rate lower $(63.3 \%)$ than the desired. In order to assess whether the response rate might have interfered in the sam- 
Table 5. Near work activitiesaccording to the two myopia progression cutoffs of $-\mathbf{0 . 5 0}$ and $-1.50 \mathrm{SE}$ in either eye.

\begin{tabular}{|c|c|c|c|c|c|c|}
\hline & & \multicolumn{2}{|c|}{-0.50 Progression } & \multicolumn{2}{|c|}{-1.50 Progression } & \multirow{2}{*}{$\begin{array}{l}\text { Total } \\
\mathrm{N}(\%)\end{array}$} \\
\hline & & $\begin{array}{c}\text { Yes } \\
\text { N(\%) }\end{array}$ & $\begin{array}{c}\text { No } \\
\text { N(\%) }\end{array}$ & $\begin{array}{c}\text { Yes } \\
\text { N(\%) }\end{array}$ & $\begin{array}{c}\text { No } \\
\text { N(\%) }\end{array}$ & \\
\hline Near Work Activities (per weekday) & Category & & & & & \\
\hline \multirow{3}{*}{ Reading for pleasure } & Never & $74(74.0)$ & $20(62.5)$ & $21(70.0)$ & $73(71.6)$ & $94(71.2)$ \\
\hline & $<1 \mathrm{~h}$ & $15(15.0)$ & $4(12.5)$ & $4(13.3)$ & $15(14.7)$ & $19(14.4)$ \\
\hline & $\geq 1 \mathrm{~h}$ & $11(11.0)$ & $8(25.0)$ & $5(16.7)$ & $14(13.7)$ & $19(14.4)$ \\
\hline \multirow{3}{*}{ Reading for study/work } & Never & $59(59.0)$ & $22(68.8)$ & $19(63.3)$ & $62(60.8)$ & $81(61.4)$ \\
\hline & $<1 \mathrm{~h}$ & $23(23.0)$ & $2(6.3)$ & $5(16.7)$ & $20(19.6)$ & $25(18.9)$ \\
\hline & $\geq 1 \mathrm{~h}$ & $18(18.0)$ & $8(25.0)$ & $6(20.0)$ & $20(19.6)$ & $26(19.7)$ \\
\hline \multirow{3}{*}{ Computer usage } & Never & $42(42.0)$ & $12(37.5)$ & $14(46.7)$ & $40(39.2)$ & $54(40.9)$ \\
\hline & $<1 \mathrm{~h}$ & $8(8.0)$ & $4(12.5)$ & $4(13.3)$ & $8(7.8)$ & $12(9.1)$ \\
\hline & $\geq 1 \mathrm{~h}$ & $50(50.0)$ & $16(50.0)$ & $12(40.0)$ & $54(52.9)$ & $66(50.0)$ \\
\hline \multirow{3}{*}{ Outdoor Activities (per weekday) } & Never & $71(71.0)$ & $21(65.6)$ & $23(76.7)$ & $69(67.7)$ & $92(69.7)$ \\
\hline & $<1 \mathrm{~h}$ & $5(5.0)$ & $2(6.3)$ & $1(3.3)$ & $6(5.9)$ & $7(5.3)$ \\
\hline & $\geq 1 \mathrm{~h}$ & $24(24.0)$ & $9(28.1$ & $6(20.0)$ & $27(26.4)$ & $33(25.0)$ \\
\hline Total* & & $100(100.0)$ & $32(100.0)$ & $30(100.0)$ & $102(100.0)$ & $132(100.0)$ \\
\hline
\end{tabular}

* 132 were considered the total because 4 had not responded the questionnaire and 2 did not have refraction results in both visits. SE - spherical equivalent; $b$ - hour.

ple representativeness, a statistical analysis comparing the school respondents and the students who did not answer to the invitation for a follow-up clinical examination was performed. The statistical analysis considering the baseline study variables as cluster sampling, gender, age, type of refractive error, visual acuity in first and second eyes tested and the mean spherical equivalent for first and second eyes tested, concluded that the last examined group (follow-up group) was representative of the baseline sample and most likely those who missed the eye examination did not influence the results of the analysis of refractive errors progression. In a study in Hong Kong, a densely populated metropolis as Sao Paulo, the response rate $(65.7 \%)$ was similar to the current study despite all attempts to increase it [22].

Several efforts were taken to increase the response rate: to exam the participants at their own schools during school hours; to search each participant by phone and/or home address; to locate the new schools for which they could have been transferred and even searching the participants through social networks by the internet. Some factors may have contributed to the non-attendance of those young individuals that include school dropout, refusal to participate due to work or recent optical prescription, refusal to pupil dilation and possible change of address. In Brazil and probably some other countries, this behavior may be justified by the lack of motivation to undergo the examination, refusal to cycloplegia, or the stigma associated with wearing glasses, all of them becoming causes of absenteeism. Even in economically high income communities, where the screening for refractive error is routine as part of health polices and there are free/accessible delivery eye care services and provision glasses, the adherence is low with high levels of absenteeism [1, 23].

The fact that only low-middle income school children from public schools were the target population has contributed to the cur- rent results since these children had lifestyle, leisure habits, access to near vision devices (smartphones, tablets, portable computers) and study tasks different from those with higher socio-economic background. On the other hand, the inclusion of school children from private schools from high economic level was attempted in the baseline study, but due to an extremely low response rate it failed [12].

In a study in China in which children aged five to 15 years of age were examined, greater myopia progression was associated with higher baseline age [3].

A meta-analysis of myopia progression including 20 randomized studies in children in urban areas of Asian and European ethnic groups, all using cycloplegic examination and samples of at least 30 children, showed progression rates dependent on baseline age. Younger children and girls had higher annual rates of progression, confirming some of the previously reported studies [22-25].

To collect reliable data on near work and outdoor activities in this low-income population was a challenge. An adapted version of an instrument used in Australian school children was too sophisticated and time-consuming to be administered to Brazilian teenagers. A culturally more appropriate instrument has to be developed for developing countries since no association was found between myopia progression and hours spent for near work and hours of outdoor activities. Maybe a shorter instrument version with straightforward questions would provide different results.

Glasses usage by both mother and father had increased the odds to myopia progression from two to four times. These results confirm the influence of familiar inheritance in the progress of myopia. In future studies it would be recommendable to have information on parent's refractive status to confirm our results. Parents 
wearing glasses can influence behavior, interests and academic goals of the children $[13,26]$. Living in the same environment, with reading activities and study, this association might be genetic or might reflect environmental influences operating within the family [27].

This follow-up study has provided population-based data on myopia progression, with comparable data with other RESC protocols worldwide in different demographic areas. The current study gathered significant results that showed low levels of myopia progression among school-age-children. It might contribute for the development of recommendations (guidelines) and/or decisionmaking strategies for eye health in this population.

\section{References}

[1]. Resnikoff S, Pascolini D, Mariotti S, Pokharel GP (2008) Global magnitude of visual impairment caused by uncorrected refractive errors in 2004. Bull WHO. 86(1): 63-70.

[2]. Pokharel GP, Negrel AD, Munoz SR, Ellwein LB (2000) Refractive error study in children: Results from Mechi Zone, Nepal. Am J Ophthalmol 129(4): 436-444.

[3]. Zhao J, Pan X, Sui R, Muñoz SR, Sperduto RD, et al. (2000) Refractive Error Study in Children: Results from Shunyi District, China. Am J Ophthalmol. 129(4): 427-435.

[4]. Maul E, Barroso S, Muñoz SR, et al. (2000) Refractive Error Study in Children: Results from La Florida, Chile. Am J Ophthalmol 129(4): 445-454.

[5]. Dandona R, Dandona L, Srinivas M, Sahare P, Narsaiah S, et al. (2002) Refractive error in children in a rural population in India. Invest Ophthalmol Vis Sci. 43(3): 615-622.

[6]. Murthy GV, Gupta SK, Ellwein LB,Muñoz SR, Pokharel GP et al. (2002) Refractive error in children in an urban population in New Delhi. Invest Ophthalmol Vis Sci 43(3): 623-631.

[7]. Naidoo KS, Raghunandan A, Mashige KP, Govender P, Holden BAet al. (2003) Refractive error and visual impairment in African children in South Africa. Invest Ophthalmol Vis Sci 44(9): 3764-3770.

[8]. He M, Zeng J, Liu Y, Xu J, Pokharel GP, et al. (2004) Refractive error and visual impairment in urban children in southern China. Invest Ophthalmol Vis Sci 45(3): 793-799.

[9]. Goh PP, Abqariyah Y, Pokharel GP, Ellwein LB (2005) Refractive error and visual impairment in school-age children in Gombak District, Malaysia. Ophthalmology 112(4): 678-685.

[10]. He M, Huang W, Zheng Y, Huang L, Ellwein LB (2007) Refractive error and visual impairment in school children in rural southern China. Ophthalmology 114(2): 374-382.

[11]. Sapkota YD, Adhikari BN, Pokharel GP, Poudyal BK, Ellwein LB (2008) The prevalence of visual impairment in school children of upper-middle socioeconomic status in Kathmandu. Ophthalmic Epidemiol 15(1): 17-23.

[12]. Salomão SR, Cinoto RW, Berezovsky A, Mendieta L, Nakanami CR, et al. (2008) Prevalence and causes of visual impairment in low-middle income school children in Sao Paulo, Brazil. Invest Ophthalmol Vis Sci 49(10):
4308-4313.

13]. Pan C, Ramamurthy D, Saw S (2012) Worldwide prevalence and risk factors for myopia. Ophthalmic Physiol Opt 32(1): 3-16.

[14]. Gao TY, Pen Z, Zhong L, Vishal J, Yi P, et al. (2014) Rationale, design, and demographic characteristics of he Handan offsprings myopia study.Ophthal Epidemiol 21(2): 124-32.

[15]. Rose KA, Morgan IG, Ip J, Kifley A, Huynh S, et al. (2008) Outdoor activity reduces the prevalence of myopia in children. Ophthalmology 115(8): 1279-1285.

[16]. Dirani M, Tong L, Tong L, Gazzard G, Zhang X, et al. (2009) Outdoor activity and myopia in Singapore teenage children. Br J Ophthalmol 93(8): 997-1000.

[17]. Stata Corporation (2013) Stata: Release 13. Statistical Software. College Station, TX. 1-414.

[18]. Alio J.L., Shabayek M.H (2006) Corneal higher order aberrations: a method to grade keratoconus. J Refract Surg 22(6): 539-545.

[19]. Lin LL, Shih YF, Hsiao CK, Chen CJ (2004) Prevalence of myopia in Taiwanese schoolchildren: 1983 to 2000. Ann Acad Med Singapore 33(1): $27-$ 33.

[20]. Morgan I, Rose K (2005) How genetic is school myopia? Prog Retin Eye Res 24(1): 1-38.

[21]. Saw SM, Nieto FJ, Katz J, Schein OD, Levy B, et al. (2000) Factors related to the progression of myopia in Singaporean children. Optom Vis Sci 77(10): 549-554

[22]. Fan DS, Lam DS, Lam RF, Lau JT, Chong KS, et al. (2004) Prevalence, incidence, and progression of myopia of school children in Hong Kong. Invest Ophthalmol Vis Sci 45(4): 1071-1075.

[23]. Saw SM, Tong L, Chua WH, Chia KS, Koh D, et al. (2005) Incidence and progression of myopia in Singaporean school children. Invest Ophthalmol Vis Sci 46(1): 51-57.

[24]. Kleinstein RN, Sinnott LT, Jones-Jordan LA, Sims J, Zadnik K (2012) New cases of myopia in children. Arch Ophthalmol 130(10): 1274-1279.

[25]. Donovan L, Sankaridurg P, Ho A, Naduvilath T, Smith EL 3rd, et al. (2012) Myopia progression rates in urban children wearing single-vision spectacles. Optom Vis Sci 89(1): 27-32.

[26]. Rose KA, Morgan IG, Smith W, Burlutsky G, Mitchell P, et al. (2008) Myopia, lifestyle, and schooling in students of Chinese ethnicity in Singapore and Sydney. Arch Ophthalmol 126(4): 527-530.

[27]. Ip JM, Huynh SC, Robaei D, Rose KA, Morgan IG, et al. (2007) Ethnic differences in the impact of parental myopia: findings from a populationbased study of 12-year-old Australian children. Invest Ophthalmol Vis Sci 48(6): 2520-2528.

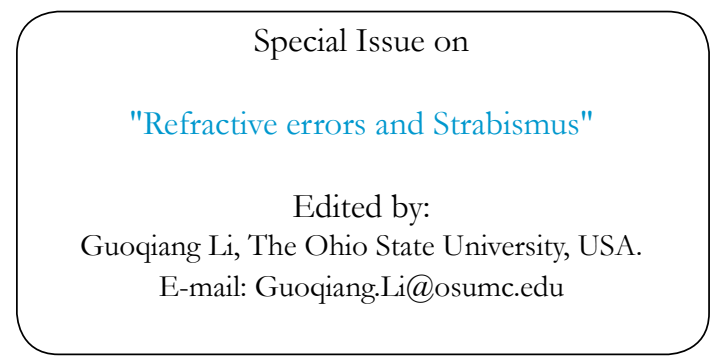

